\title{
TREATMENT OF THE CERVICAL SPINE
}

\author{
Neurosurgical Focus, January 2002 \\ Topic Editor: Vincent Traynelis, M.D. \\ Division of Neurosurgery, The University of Iowa Hospitals and Clinics, Iowa City, Iowa
}

In this issue of Neurosurgical Focus we investigate the surgical treatment of cervical spinal disorders. The response to the call for papers was outstanding, and a great number of excellent articles were accepted for publication.

The development of new techniques and implementation instrumentation is driven by the desire to improve patient-related care. Despite good intentions, what is new does not always prove to be beneficial. It is important to assess every "advance" to determine which is worthwhile. In the first group of articles the authors examine the clinical experience with various vertebral interbody spacers or cages. These devices are on the cutting edge, and their use is both controversial and thought provoking.

In the next group of articles the authors focus on advances in surgical technique. I have found that screw fixation of the atlantal mass performed via the posterior approach is exceedingly useful in selected cases. This technique is well described in two detailed articles. Papers on the anterior exposure of the cervical thoracic junction, rigid posterior cervical subaxial fixation, a new lami- noplasty technique, and cervical pediculotomy complete this section.

In the final section the authors address diverse topics in cervical spine surgery, which together may be considered more standard treatments. Dr. Kalfas has written an outstanding review of the role of corpectomy in the management of cervical spondylosis. Other articles include a discussion of anterior decompression in the management of ossification of the posterior longitudinal ligament, early results of the Atlantis plate system, and surgical management of occipital neuralgia via C-2 gangliectomy. The final paper is an important contribution in which the authors endeavor to standardize the nomenclature of anterior plate systems.

The co-editors of this edition were Juan Bartolomei, M.D., Benard Guiot, M.D., Robert Hacker,M.D., Andrew Dailey, M.D., and Rick Sasso, M.D. Each of these coeditors provided thoughtful review and critique of the submitted papers. This evening and weekend work is essential, and I greatly appreciate their efforts. 